\title{
COMPUTER SIMULATION OF INTERMITTENT CURRENT MODE OF DC ELECTRIC DRIVE WITH THREE-PHASE CONTROLLED RECTIFIER
}

\begin{abstract}
Introduction. The mode of intermittent current for DC motor with three-phase thyristor rectifier appears in the idle intervals of some mechanisms. Active and passive filters reduce the variable component of the rectified voltage. The capacitance of the capacitors filter is determined by the effective value of the variable component of the rectified voltage. Problem. Necessity of developing an analytical method for calculating the effective value of the variable component of the rectified voltage in the intermittent current mode, taking into account three parameters: the control angle, the electromagnetic time constant of the armature circuit and the load current. Purpose. To determine the dependence of the effective value of the variable component of the rectified voltage for three parameters in theintermittent current mode. Methodology. The effective value of the variable component of the rectified voltage is suggested to be determined through the voltage pulsations factor as the ratio of the effective value of the variable component of the rectified voltage to its constant component. The dependence of the pulsations factor from the parameters of the mode is determined using computer simulation of the mode for intermittent current. Results. The computer model is developed in the software package Simulink, which allows to change each parameter of the mode separately while stabilizing the other two. Numerical dependences of the pulsation factor on each parameter are obtained. The analytical dependence of the voltage pulsations factor on three influencing values was obtained by the method of experiment planning. Originality. For the first time, method has been developed for calculating pulsation factor of the rectified voltage and calculating the effective value of the variable component in the mode of intermittent currents, taking into account three parameters. Practical value. The proposed method will allow to rationally determine the capacity of the capacitors of active and passive filters and increase the efficiency of electromechanical power conversion by reducing the variable component of the rectified voltage. References 6, tables 7, figures 5.
\end{abstract}

Key words: thyristor rectifier, voltage pulsations, angle of control, intermittent current.

Режим прерывистого тока вентильных электроприводов постоянного тока появляется в интервалах холостого хода механизмов. Расчет емкости конденсаторов фильтра выполняется через действующее значение переменной составляющей выпрямленного напряэсения и поэтому возникает задача разработки методики для ее расчета через коэффициент пульсаций напряжения с учетом угла управления, электромагнитной постоянной времени цепи якоря и тока нагрузки. Выражение для расчета коэффициента пульсаций напряжсения с учетом влияющих факторов, полученное методом планирования эксперимента на основе компьютерного моделирования в программном пакете Simulink, позволяет определить емкость конденсаторов фильтра и повысить эффективность электромеханического преобразования электроэнергии за счет снижения переменной составляющей. Библ. 6, табл. 7, рис. 5.

Ключевые слова: тиристорный выпрямитель, пульсации напряжения, угол управления, прерывистый ток.

Actuality of the topic. In modern, controlled DC electric drives, semiconductor (transistor, thyristor) controlled rectifiers are widely used.

In the driven by the network thyristor rectifiers, which are now continuing to be serially produced in Ukraine, there are modes of intermittent currents during idle motor operation. Intermittent currents reduce the efficiency of the motor since the variable component of the current does not create a mechanical torque on the shaft.

To smooth out the rectified voltage, filters are used: active or resonant, which in their circuits have a capacitor [1-4]. For resonant filters, the capacity of a capacitor is determined by the condition of equality of reactor and capacitor energies

$$
C=L \cdot \sum I_{k}^{2} / \sum U_{k}^{2},
$$

where $L$ is the reactor inductance; $I_{k}, U_{k}$ are the effective values of harmonic components of current and voltage, respectively.

From (1) the need to determine the effective value of the variable components of the rectified voltage including this for the mode of intermittent currents follows.

Analysis of publications. To determine the effective value of the variable components of the rectified voltage in the mode of intermittent currents it is necessary to choose a generalizing parameter that does not depend on the motor power. This parameter is the voltage pulsation coefficient $K_{p U}$ [1-4]

$$
K_{p U}=\sqrt{\sum U_{k}^{2}} / U_{d 0}=\sqrt{U_{d D}^{2}-U_{d 0}^{2}} / U_{d 0},
$$

where $U_{d 0}$ is the average value (constant component) of rectified voltage, $U_{d D}$ is the effective value of the rectified voltage.

Then the effective value of the alternating components of the rectified voltage is equal

$$
\sqrt{\sum U_{k}^{2}}=K_{p U} \cdot U_{d 0}
$$

In the well-known literature, for example, in [4], the graphoanalytic method for determining the voltage pulsation coefficient for DC motors is proposed only for the case of its operation with nominal load and nominal speed. But this method, on the one hand, is rather uncomfortable and cumbersome, and on the other hand, creates a certain error in the calculations, since, as a rule, DC motors operate with a load and a speed less than nominal. Proceeding from this, it is necessary to develop a more convenient and more precise method for determining the voltage pulsation coefficient for the mean values of load and speed, if during the process of operation the latter change in a certain range. The modern approach to determining the pulsation coefficient is a

(c) Y.V. Kovalova 
method of computer modeling, but this method is not sufficiently studied in known literary sources.

The goal of the work is by means of computer simulation to determine the dependence of the pulsation coefficient of the output voltage of the three-phase controlled rectifier in the mode of intermittent currents on the angle of control and load parameters and to develop an analytical method for its calculation.

Results of investigations. The complex nature of the dependence of the voltage pulsation coefficient on the parameters of the mode excludes the possibility of obtaining it in an analytical form. Therefore, this dependence must be determined experimentally with further approximation by an analytic polynomial by the method of experiment planning. Since DC motors relate to a class of deterministic systems, it is rational to carry out a computer experiment. The computer model of a three-phase controlled rectifier (for example, a thyristor rectifier) with a DC motor in the software package Simulink [5] is presented in Fig. 1. The model consists of the following elements: three-phase voltage system performed on single-phase alternating voltage sources, three-phase thyristor rectifier with pulse-phase control system, ammeters, voltmeters, blocks for calculating the constant (average) components and effective values of voltage and current, display and oscilloscope. The constant component of the rectified voltage is determined by the block "Magnitude signal", and the effective value by the blocks "signal rms". The model of the DC motor is represented by the electromotive force (EMF) of the armature $E_{a}$, the active resistance $R_{a}$, and the inductance of the armature $L_{a}$. EMF of the armature is represented by a source of constant voltage.

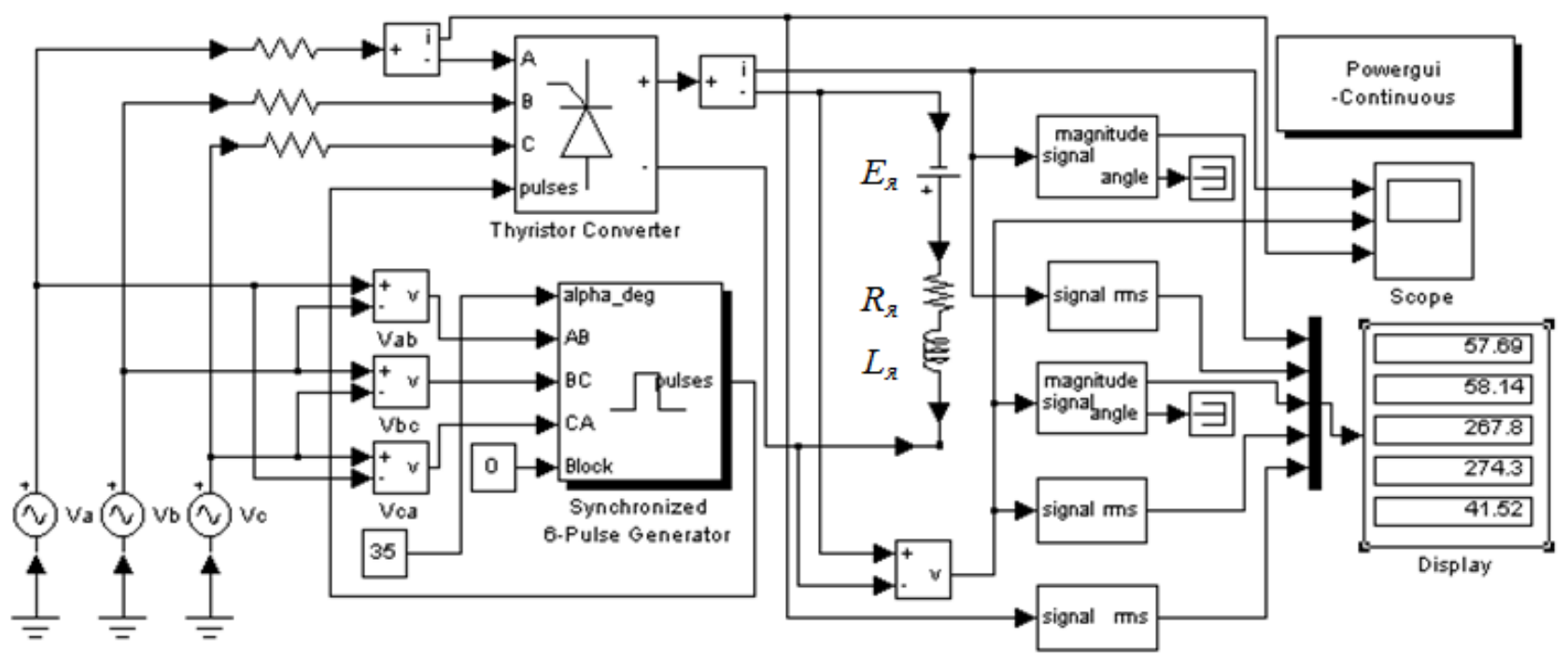

Fig. 1. Simulink-model of a DC electric drive with thyristor rectifier

The value of the armature EMF is given by the $E_{a}$ block with the minus sign, since on the circuit it is connected non-opposite for rectifier voltage, due to the peculiarities of connection of blocks in the Simulink software package. Fig. 2 shows the obtained oscillograms of the voltage and current of the armature on the model.

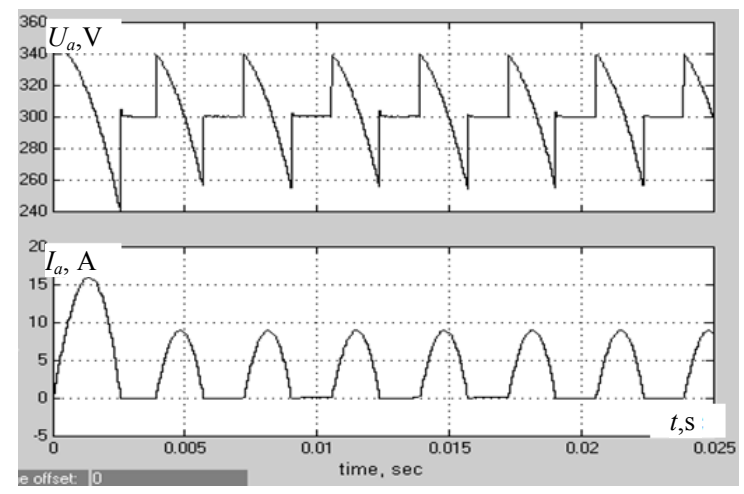

Fig. 2. Calculated oscillograms of voltage and current of the winding and armature

According to the method of planning the experiment, the computer experiment is carried out as follows. We determine the dependences of the voltage pulsation coefficient separately from each of the influencing factors (the angle of control of the thyristors, the electromagnetic time constant of the armature circuit and the load on the motor shaft) with stabilization of the other two. Stabilization of a constant current component is realized by adjusting the speed of the motor through the appropriate regulation of the armature EMF by the iteration method, that is, the successive approximation of the value of the EMF to the required value of current. Let's calculate the voltage pulsation coefficient in the mode of intermittent currents for the motor $4 \Pi Ф 180 \mathrm{M}$ with parameters $P=45 \mathrm{~kW}, U=440 \mathrm{~V}, n=1060 \mathrm{rpm}$, $I_{\text {nom }}=115 \mathrm{~A}, R_{a}=50 \mathrm{~m} \Omega, L_{a}=4 \mathrm{mH}, T_{a}=0.08 \mathrm{~s}$. Experimental results are presented in Table 1-3.

Table 1

Calculation of the voltage pulsation coefficient dependence on the control angle at $I_{0}=$ const $=3.46 \mathrm{~A}, T_{a}=$ const $=0.08 \mathrm{~s}$

\begin{tabular}{|c|c|c|c|}
\hline$\alpha$, degrees & 80 & 110 & 140 \\
\hline$U_{d 0}, \mathrm{~V}$ & 318.9 & 304.2 & 280.8 \\
\hline$U_{d D}, \mathrm{~V}$ & 319.7 & 305.4 & 282.3 \\
\hline$\sqrt{\sum U_{k}^{2}}, \mathrm{~V}$ & 22.6 & 27.05 & 29.06 \\
\hline$K_{p U}$ & 0.07 & 0.09 & 0.1 \\
\hline
\end{tabular}


Table 2

Calculation of the voltage pulsation coefficient dependence on the time constant at $I_{0}=$ const $=3.46 \mathrm{~A}, \alpha=$ const $=110$ degrees

\begin{tabular}{|c|c|c|c|}
\hline$T_{a}, \mathrm{~s}$ & 0.06 & 0.08 & 0.1 \\
\hline$U_{d 0}, \mathrm{~V}$ & 308.7 & 304.2 & 300.2 \\
\hline$U_{d D}, \mathrm{~V}$ & 309.4 & 305.3 & 301.6 \\
\hline$\sqrt{\sum U_{k}^{2}}, \mathrm{~V}$ & 20.8 & 25.89 & 29.03 \\
\hline$K_{p U}$ & 0.07 & 0.09 & 0.1 \\
\hline
\end{tabular}

Table 3

Calculation of the voltage pulsation coefficient dependence on the load at $\alpha=$ const $=110$ degrees, $T_{a}=$ const $=0.08 \mathrm{~s}$

\begin{tabular}{|c|c|c|c|}
\hline$E_{a}, \mathrm{~V}$ & 319.5 & 304 & 293.6 \\
\hline$U_{d 0}, \mathrm{~V}$ & 319.6 & 304.2 & 293.9 \\
\hline$U_{d D}, \mathrm{~V}$ & 319.8 & 305.3 & 296 \\
\hline$\sqrt{\sum U_{k}^{2}}, \mathrm{~V}$ & 11.31 & 25.89 & 35.2 \\
\hline$K_{p U}$ & 0.04 & 0.08 & 0.12 \\
\hline
\end{tabular}

According to the results of the research, the corresponding graphs of the dependences of the voltage pulsation coefficient from the angle of control, the electromagnetic time constant of the armature circuit and the load current, are built and shown in Fig. 3-5.

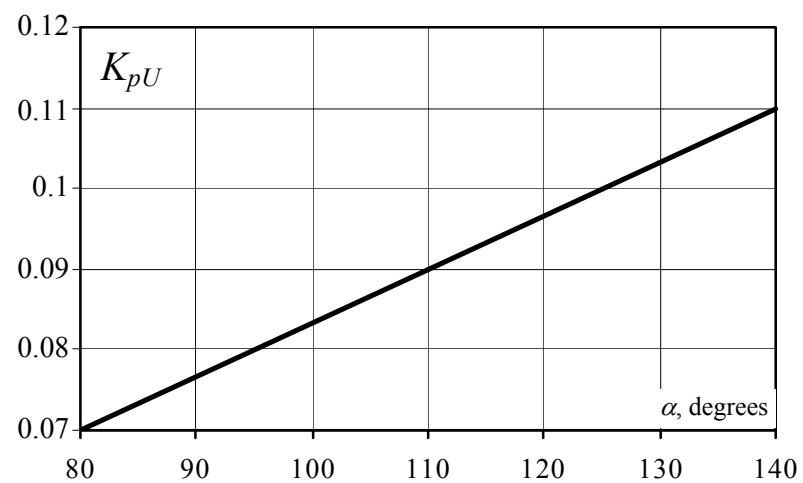

Fig. 3. Voltage pulsation coefficient dependence on the angle of control

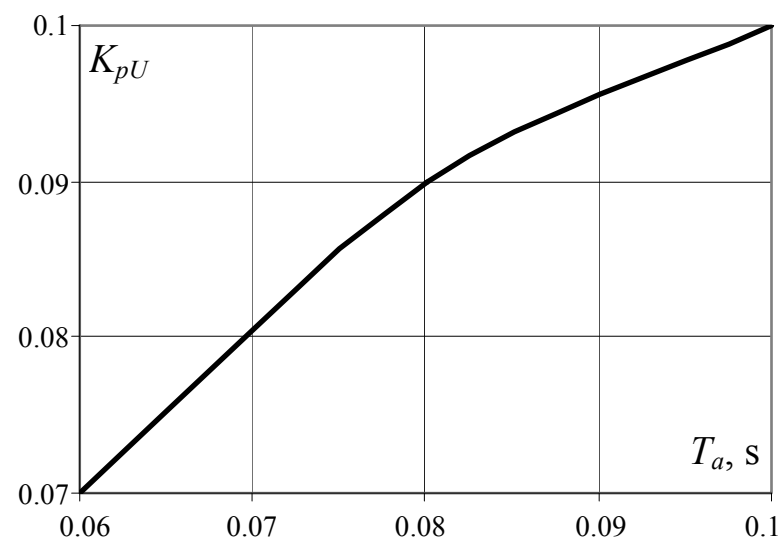

Fig. 4. Voltage pulsation coefficient dependence on the electromagnetic time constant of the armature circuit

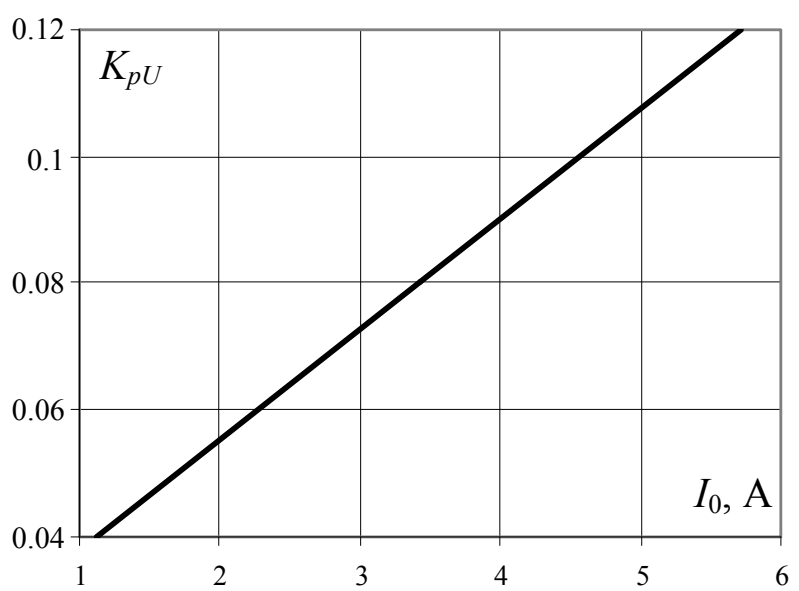

Fig. 5. Voltage pulsation coefficient dependence on the load current

For the approximation of the dependence of the voltage pulsation coefficient on the three influencing factors, we apply the experiment planning method. According to the methodology [6], we look for a polynomial for calculating the voltage pulsation coefficient in the form:

$$
\begin{aligned}
& K_{p U}=b_{0}+b_{1} \alpha+b_{2} T_{a}+b_{3} I_{0}^{*}+b_{12} \alpha T_{a}+ \\
& +b_{13} \alpha I_{0}^{*}+b_{23} T_{a} I_{0}^{*}+b_{123} \alpha T_{a} I_{0}^{*},
\end{aligned}
$$

where $I_{0}{ }^{*}=I_{0} / I_{\text {nom }}$ is the relative value of the constant current component.

The values of the factors in full experiment, their coding and variations are shown in Table 4.

Table 4

The values of factors at the full factor experiment, their coding and variations

\begin{tabular}{|c|c|c|c|}
\hline$\alpha$, degrees & 80 & 110 & 140 \\
\hline$T, \mathrm{~s}$ & 0.06 & 0.08 & 0.1 \\
\hline$L, \mathrm{H}$ & 0.003 & 0.004 & 0.005 \\
\hline$I_{0}{ }^{*}$ & 0.01 & 0.03 & 0.05 \\
\hline$I, \mathrm{~A}$ & 1.15 & 3.45 & 5.75 \\
\hline Code of factors & - & 0 & + \\
\hline
\end{tabular}

Experimental results are presented in Table 5.

Table 5

Results of the full factor experiment

\begin{tabular}{|c|c|c|c|c|c|}
\hline No. & $E, \mathrm{~V}$ & $U_{d 0}, \mathrm{~V}$ & $U_{d D}, \mathrm{~V}$ & $\sqrt{\sum U_{k}^{2}}, \mathrm{~V}$ & $K_{p U}$ \\
\hline 1 & 388 & 332.9 & 335 & 37.451 & 0.112 \\
\hline 2 & 285 & 302.8 & 309.1 & 62.088 & 0.205 \\
\hline 3 & 367 & 328.9 & 333.1 & 52.729 & 0.16 \\
\hline 4 & 260 & 296.3 & 300.5 & 50.066 & 0.169 \\
\hline 5 & 324.5 & 315.5 & 316.6 & 26.369 & 0.084 \\
\hline 6 & 213 & 275.5 & 277.5 & 33.257 & 0.121 \\
\hline 7 & 303.6 & 306.3 & 308.4 & 35.929 & 0.117 \\
\hline 8 & 186.1 & 262.6 & 266.3 & 44.237 & 0.168 \\
\hline 9 & 304.4 & 304.6 & 308.1 & 46.308 & 0.152 \\
\hline
\end{tabular}

As a result of calculations of the coefficients of the polynomial (4), the formula of the pulsation coefficient is obtained 


$$
\begin{aligned}
& K_{p U}=0.142+0.024 \alpha+0.012 T_{a}-0.02 I_{0}^{*}- \\
& -0.009 \alpha T_{a}-0.002 \alpha I_{0}^{*}+0.009 T_{a} I_{0}^{*}+0.012 \alpha T_{a} I_{0}^{*} .
\end{aligned}
$$

We determine the error of the calculated values of the voltage pulsation coefficient by the formula (5) relative to the obtained on the model. The results of calculations of errors are summarized in Table 6.

Table 6

Results of calculation of relative error

\begin{tabular}{|c|c|c|c|}
\hline $\begin{array}{c}\text { No. of } \\
\text { experiment }\end{array}$ & $\begin{array}{c}\text { Exact } \\
\text { values }\end{array}$ & $\begin{array}{c}\text { Calculated } \\
\text { values }\end{array}$ & $\begin{array}{c}\text { Relative } \\
\text { error, \% }\end{array}$ \\
\hline 1 & 0.112 & 0.16 & -43 \\
\hline 2 & 0.205 & 0.19 & 7 \\
\hline 3 & 0.16 & 0.16 & 0 \\
\hline 4 & 0.169 & 0.19 & -12 \\
\hline 5 & 0.084 & 0.16 & -9 \\
\hline 6 & 0.121 & 0.19 & -57 \\
\hline 7 & 0.117 & 0.16 & -37 \\
\hline 8 & 0.168 & 0.19 & -13 \\
\hline
\end{tabular}

To calculate the effective value of the voltage pulsations, we must determine the relative values of the average speed and the constant component of the armature voltage $\omega_{a}{ }^{*}=U_{0}{ }^{*}=\omega_{a} / \omega_{\text {nom }}=U_{0} / U_{\text {nom }}{ }^{*}$ which depend on the angle of control of the thyristors. Dependence of the relative value of the constant component of the armature voltage on the angle of control obtained on the model is shown in Table 7.

As a result of the approximation of the regulatory characteristic by the method of the least squares [6] according to Table 7 we obtain the formulas for the relative value of the constant component of the voltage and the control angle $U_{d 0}{ }^{*}=0.831-0.077 \alpha, \alpha=\left(0.831-U_{d 0}{ }^{*}\right) / 0.077$, where $\alpha$ is the angle of control in radians.

Table 7

Dependence of the relative value of the constant component of the armature voltage on the control angle

\begin{tabular}{|c|c|}
\hline $\begin{array}{c}\text { Thyristors control } \\
\text { angle, degrees }\end{array}$ & $\begin{array}{c}\text { Relative value of the } \\
\text { armature voltage, } U_{d 0}{ }^{*}\end{array}$ \\
\hline 80 & 0.86 \\
\hline 110 & 0.65 \\
\hline 140 & 0.23 \\
\hline
\end{tabular}

Thus, the method for determining the effective value of the components of the voltage components is as follows:

1. We set the speed $\omega_{a}{ }^{*}$, calculate $U_{d 0}{ }^{*}$ and $\alpha$;

2 . We set the loading torque and determine the relative value of the constant current component $I_{0}{ }^{*}=M_{a} / M_{\text {nom }}$;

3. We determine the voltage pulsation coefficient by the formula (5);

4. We determine the effective value of the variable voltage component by the formula (3).

\section{Conclusions.}

On the basis of computer simulation an analytical method for calculating the pulsation coefficient and the effective value of the variable component of the rectified voltage in the mode of intermittent currents is developed.

The proposed methodology will allow us to efficiently determine capacitances of filter capacitors and increase the efficiency of electromechanical transformation of electric energy by reducing the variable component of the rectified voltage.

\section{REFERENCES}

1. Afonso J., Couto C., Martins J. Active filters with control based on $\mathrm{p}-\mathrm{q}$ theory. IEEE Industrial Electronics Society Newsletter, 2000, vol.47, no.3, pp. 5-10.

2. Soares V., Verdelho P., Marques G.D. An instantaneous active and reactive current component method for active filters. IEEE Transactions on Power Electronics, 2000, vol.15. no.4, pp. 660-669. doi: 10.1109/63.849036.

3. Kovalova Y.V. Determination of the ripple factor of the voltage of single-phase three sided rectifier. Lighting engineering and power engineering, 2016, no.3, pp. 4-7.

4. Sen'ko V.I. Sylova elektronika [Power electronics]. Kiev, IZMN Publ., 1999. 214 p. (Ukr).

5. German-Galkin S.G. Komp'iuternoe modelirovanie poluprovodnikovykh sistem v MATLAB 6.0 [Computer model of the semiconductor systems in MATLAB 6.0]. Saint Petersburg, CORONA Publ., 2007. 320 p. (Rus).

6. Vlasov K.P. Metody issledovanii $i$ organizatsiia eksperimentov [The method of investigation and organization experiments]. Kharkiv, Gumanitarnyi Center Publ., 2002. 256 p. (Rus).

Received 04.04.2018

Y.V. Kovalova, Candidate of Technical Sciences,

O.M. Beketov National University of Urban Economy in Kharkiv,

17, Marshal Bazhanov Str., Kharkiv, 61002, Ukraine, phone +38066 9797302, e-mail: kovalova.jv@gmail.com

How to cite this article:

Kovalova Y.V. Computer simulation of intermittent current mode of DC electric drive with three-phase controlled rectifier. Electrical engineering \& electromechanics, 2018, no.4, pp. 20-23. doi: 10.20998/2074-272X.2018.4.03. 